worsening of renal function. These data help to better clarify the pathophysiology of type 2 cardiorenal syndrome, and raise several questions about the best therapeutic approach for these patients.

\section{References}

[1] Damman K, Jaarsma T, Voors AA, Navis G, Hillege HL, van Veldhuisen DJ. COACH investigators. Both in- and out-hospital worsening of renal function predict outcome in patients with heart failure: results from the Coordinating Study Evaluating Outcome of Advising and Counseling in Heart Failure (COACH). Eur J Heart Fail 2009;11:847-54.

[2] Ronco C, Haapio M, House AA, Anavekar N, Bellomo R. Cardiorenal syndrome. J Am Coll Cardiol 2008:52:1527-39.

[3] Mullens W, Abrahams Z, Francis GS, Sokos G, Taylor DO, Starling RC, Young JB, Tang $\mathrm{WH}$. Importance of venous congestion for worsening of renal function in advanced decompensated heart failure. J Am Coll Cardiol 2009;53:589-96.
[4] Damman K, Voors AA, Hillege HL Navis G, Lechat P, van Veldhuisen DJ, Dargie HJ, CIBIS-2 Investigators and Committees. Congestion in chronic systolic heart failure is related to renal dysfunction and increased mortality. Eur J Heart Fail 2010;12:974-82.

[5] Coats AJS, Shewan LG. Statement on Authorship and Publishing Ethics in the International Journal of Cardiology. Int J Cardiol 2011;153:239-40.

[6] Rudski LG, Lai WW, Afilalo J, Hua L, Handschumacher MD, Chandrasekaran K, Solomon SD, Louie EK, Schiller NB. Guidelines for the echocardiographic assessment of the right heart in adults: a report from the American Society of Echocardiography endorsed by the European Association of Echocardiography, a registered branch of the European Society of Cardiology, and the Canadian Society of Echocardiography. J Am Soc Echocardiogr 2010;23:685-713.

[7] Jessup M, Costanzo MR. The cardiorenal syndrome: do we need a change of strategy or a change of tactics? J Am Coll Cardiol 2009;53:597-9.

\title{
Baroreflex sensitivity and heart rate variability are enhanced in patients with anorexia nervosa
}

\author{
Fabrizio Jacoangeli ${ }^{a}$, Federica Staar Mezzasalma ${ }^{a}$, Giuseppe Canto ${ }^{a}$, Francesca Jacoangeli ${ }^{b}$, Carmela Colica ${ }^{\mathrm{c}}$, \\ Antonino de Lorenzo ${ }^{\mathrm{d}}$, Ferdinando Iellamo ${ }^{\mathrm{e}, \mathrm{f}, *}$ \\ a Department of Internal Medicine, Division of Clinical Nutrition, Parenteral Therapy and Eating, University Tor Vergata Rome, Italy \\ b Department of Clinical and Molecular Medicine, II Medical Faculty, University La Sapienza, Rome, Italy \\ c Department of Pharmacology, CNR, ISN, University Magna Graecia, Roccelletta di Borgia, Catanzaro, Italy \\ d Division of Human Nutrition, Department of Neuroscience, University of Rome Tor Vergata, Italy \\ e Istituto di Ricovero e Cura a Carattere Scientifico San Raffaele Pisana, Roma, Italy \\ ${ }^{\mathrm{f}}$ Department of Internal Medicine, Università Tor Vergata, Roma, Italy
}

\section{A R T I C L E I N F O}

\section{Article history:}

Received 19 September 2012

Accepted 28 October 2012

Available online 15 November 2012

\section{Keywords:}

Anorexia nervosa

Baroreflex sensitivity

Heart rate variability

Autonomic nervous system

Anorexia nervosa (AN) is a major eating disorder characterized by a voluntary restriction of dietary intake due to an obsessive fear of gaining weight and to distortion of body shape [1]. AN represents a tragic medical problem in young people in western societies. It is widely reported that patients with AN feature an enhanced mortality rate as compared with age-matched healthy subjects [2], which has been mainly ascribed to cardiac complications, namely ventricular arrhythmias and sudden death [3]. Inasmuch as alterations in the autonomic control of the heart, namely enhanced sympathetic and reduced parasympathetic activity, play a major role in the occurrence of arrhythmic events [4] several studies have searched for possible abnormalities in cardiac autonomic nervous system activity in AN. However the results have been inconsistent [5-7]. One aspect of neural cardiovascular regulation that has received scant attention in AN is baroreflex control of heart rate, despite impairment in baroreflex sensitivity (BRS), an index of the reflex vagal control of the sinoatrial

\footnotetext{
* Corresponding author at: IRCCS San Raffaele Pisana, Dipartimento di Medicina Interna, Università di Roma "Tor Vergata", Via O. Raimondo, 8, 00173, Roma, Italy. Tel.: + 3906 20900560; fax: + 390672594263 .

E-mail address: iellamo@med.uniroma2 (F. Iellamo).
}

node, carries the most relevant negative prognostic information in cardiovascular diseases [4]. In the present study we determined BRS in patients with AN.

We enrolled 20 female patients (age $27 \pm 9.4$ years) with restricting type of AN (Table 1) without comorbidities and not taking any medication at that time that could had interfered with the activity of the autonomic nervous system and 15 age-matched healthy female controls (age 30.2 \pm 4.7 ) BRS was assessed by the spontaneous sequences method, which reflects mainly vagally mediated baroreceptor-cardiac responses [8], during $10 \mathrm{~min}$ of supine rest. The standard deviation of mean R-R interval was also assessed as a measure of heart rate variability (HRV) because of its linking with a greater arrhythmic-related mortality rate in CV disease [4]. Full characterization of hormonal and metabolic status was determined. The continuous ECG signal was obtained with a modified C5 lead, connecting the electrodes to an analog preamplifier. Arterial blood pressure was continuously and noninvasively measured by Finapres. All participants gave written informed consent to the study and the protocol was approved by the Ethics Committee of University of Rome Tor Vergata. The authors of this manuscript certify that they complied with the Principles of Ethical Publishing in the International Journal of Cardiology [9]. Normally distributed variables were compared using unpaired $t$ test, whereas nonnormally distributed variables were compared using a Wilcoxon rank sum test.

Table 1

Baseline characteristics of patients.

\begin{tabular}{ll}
\hline Weight before onset of anorexia nervosa $(\mathrm{kg})$ & $52.7 \pm 7.6$ \\
Duration of anorexia nervosa (months) & $96 \pm 99$ (range:6-312) \\
Duration of amenorrea (months) & $53 \pm 49$ \\
Weight at the onset of amenorrhea $(\mathrm{kg})$ & $46.5 \pm 5.8$ \\
\hline
\end{tabular}

Data are expressed as mean \pm SD. 
BMI was significantly lower in AN patients than in controls (15.1 \pm $1.2 \mathrm{~kg} / \mathrm{m}^{2}$ vs $\left.21.6 \pm 2.32 \mathrm{~kg} / \mathrm{m}^{2}, \mathrm{p}<0.001\right)$. Heart rate and systolic and diastolic arterial blood pressures were significantly lower, whereas BRS and HRV were significantly greater in AN patients than in controls (Table 2). QT interval was significantly longer in AN patients, although its duration was within the normality range. Corrected QT interval did not significantly differ between AN patients and controls. No relationship was found between illness duration and BMI with both BRS and HRV. As expected, IGF-1, FT3, estrogen and LH were significantly lower in AN patients, whereas plasma electrolytes were within normal range in both groups.

The main finding of this study is that in patients with restricting type of AN BRS and HRV, two major negative prognostic indicators of arrhythmic death, are not depressed, rather they are augmented, indicating an enhanced parasympathetic control over the heart. Further supporting the concept of increased vagal control (with a lack of enhanced sympathetic activity) to the cardiovascular system, were our findings of lower HR and blood pressure values in AN patients compared to controls, although we admit that no direct or indirect measure of sympathetic regulation has been investigated as a part of this study. The mechanism(s) of the enhanced parasympathetic control of HR in AN patients are not readily apparent and this study, by its nature, could not answer this question. They may involve adaptations in peripheral and central neural pathways, although modifications in the responsiveness of the sinoatrial node might also contribute. Anyway, the enhanced vagal control should exert cardiac protection against life-threatening arrhythmias. The possibility that the increased vagal activation could provoke, through the induction of bradycardia, an increase in temporal dispersion of the refractory period and significantly reduce the threshold for ventricular fibrillation cannot be ruled out, but this mechanism has been described only in myocardial ischemia and infarction [10], that is, pathological findings not reported in young AN patients. A limitation of the study is its cross-sectional design, that prevented us from drawing any conclusion on the outcome of AN patients. However, the present study was not designed for this purpose. Strengths of this study include the full characterization of hormonal and metabolic status in both AN patients and controls, not addressed in previous studies, and the enrollment of only outpatients with restricting type of AN, whereas previous studies [5-7] included both restricting and binge-eating/ purging types of AN.
Table 2

Arterial blood pressure, heart rate, baroreflex sensitivity and heart rate variability.

\begin{tabular}{lcc}
\hline & Anorexic patients & Controls \\
\hline Systolic arterial pressure $(\mathrm{mm} \mathrm{Hg})$ & $100(90-106)^{*}$ & $120(116-124)$ \\
Diastolic arterial pressure $(\mathrm{mm} \mathrm{Hg})$ & $70(57-71)^{*}$ & $75(71-80)$ \\
Heart rate $($ beats/min) & $46(45-54)^{*}$ & $72(67-77)$ \\
BRS $(\mathrm{ms} / \mathrm{mm} \mathrm{Hg})$ & $31(19-55)^{*}$ & $11(9-12)$ \\
HRV $(\mathrm{ms})$ & $91(63-157)^{*}$ & $53(38-74)$ \\
\hline
\end{tabular}

Data are expressed as median and interquartile range. BRS, baroreflex sensitivity; HRV heart rate variability (standard deviation of mean $\mathrm{R}-\mathrm{R}$ interval).

$* \mathrm{P}<0.05$ vs controls.

In conclusion, this study indicates that in patients with restricting type of AN, BRS and HRV, two major negative prognostic indicators of arrhythmic death, are augmented, indicating an enhanced parasympathetic control over the heart. This would argue against an impairment in autonomic regulation in the increased cardiac mortality in AN, suggesting that factors other than impairments in autonomic cardiac control are involved.

\section{References}

[1] American Psychiatric Association. Diagnostic and statistical manual of mental disorders. 4th ed. Washington, DC: American Psychiatric Association; 1994.

[2] Birmingham CL, Su J, Hlynsky JA, Goldner EM, Gao M. The mortality rate from anorexia nervosa. Int J Eat Disord 2005;38:143-6.

[3] Neumarker KJ. Mortality and sudden death in anorexia nervosa. Int J Eat Disord 1997;21:205-12.

[4] La Rovere MT, Bigger JT, Marcus FI, Mortara A, Schwartz PJ, for the ATRAMI Investigatores. Baroreflex sensitivity and hearth rate variability in prediction of total cardiac mortality after myocardial infarction. Lancet 1998;351:478-84.

[5] Cong ND, Saikawa T, Ogawa R, Hara M, Takahashy N, Sakata T. Reduced 24 hour ambulatory blood pressure and abnormal heart rate variability in patients with Dysorexia nervosa. Heart 2004;90:563-4.

[6] Rechlin T, Weis M, Ott C, Bleichne F, Joraschky P. Alterations of autonomic cardiac control in anorexia nervosa. Biol Psychiatry 1998;43:358-63.

[7] Melanson EL, Donahoo WT, Krantz MJ, Poirier P, Mehler PS. Resting and ambulatory hearth rate variability in chronic anorexia nervosa. Am J Cardiol 2004;94:1217-20.

[8] Iellamo F, Legramante JM, Massaro M, et al. Spontaneous baroreflex modulation of heart rate and heart rate variability during orthostatic stress in tetraplegics and healthy subjects. J Hypertens 2001;19:2231-40.

[9] Coats AJS, Shewan LG. Statement on authorship and publishing ethics in the International Journal Of Cardiology. Int J Cardiol 2011;153:239.

[10] Scherlag BJ, Kabell G, Harrison L, Lazzara R. Mechanisms of bradicardia-induced ventricular arrhytmias in myocardial ischemia and infarction. Circulation 1982;65:1429-34. 